Ashish C. Suthar ${ }^{1}$, Anand Deshmukh², Vijaya Babu³, Vijaya S. Mohan ${ }^{4}$, Madhukar V. Chavan ${ }^{5}$, Dutta Kumar ${ }^{6}$, Vijaysingh Chauhan ${ }^{1}$, Somesh Sharma7, Mahesh Sharma ${ }^{8}$

${ }^{1}$ Piramal Enterprises Limited, Mumbai, Maharashtra, India

${ }^{2}$ Tanay Clinic, Main Road Loha, Nanded, Maharashtra, India

${ }^{3}$ A.L. Govt. Ayu. College, Warangal, Andhra Pradesh, India

${ }^{4}$ Divya Poly Clinic, Narayan guda, Hyderabad, Andhra Pradesh, India

${ }^{5}$ Dhanvantari Clinic, Jiyaguda, Hyderabad, Andhra Pradesh, India

${ }^{6}$ Advance Rheumatology Center, Koutilya $1^{\text {st }}$ Floor, Medinova Complex, Somajiguda, Hyderabd, Andhra Pradesh, India

7Piramal Enterprises Limited

${ }^{8}$ Aarogya Hospital, M.J. Market, Hyderabad, Andhra Pradesh, India

\title{
Efficacy and safety of Glycebal (PDM011011) capsules as adjuvant therapy in subjects with type 2 diabetes mellitus: an open label, randomized, active controlled, phase II trial
}

\section{ABSTRACT}

Background. Momordica charantia is a medicinal plant used traditionally for treatment of various diseases including diabetes.

Objective. To evaluate the efficacy and safety of PDM011011 capsules ( $1.2 \mathrm{~g} /$ day) as an adjuvant therapy in subjects with type 2 diabetes mellitus (T2DM).

Methods. Each PDM011011 capsule contained $400 \mathrm{mg}$ dry fruit juice powder of Momordica charantia. Ninety three T2DM patients receiving at least one oral hypoglycemic treatment were screened. The eligible 85 subjects were randomized into 3:1 ratio in drug treatment (PDM011011 capsules) and placebo arm. Sixty-four patients received three $400 \mathrm{mg}$ PDM011011 capsules ( $1.2 \mathrm{~g} /$ day) while 21 patients received three placebo capsules per day for 90 days respectively. The primary efficacy endpoints were mean change in FPG, PPG level and $\mathrm{HbA}_{1 \mathrm{c}} \%$ from baseline to day 30,60 and 90 after interventions.

Address for correspondence:

Dr. Ashish C. Suthar

Piramal Enterprises Limited, Light Hall - A wing, Saki Vihar Road,

Chandivali, Andheri - (E), Mumbai-400 072

Phone: 02230818210

Fax: 02230818036

e-mail: ashish.suthar@piramal.com

Clinical Diabetology 2016, 5, 3, 88-94

DOI: 10.5603/DK.2016.0015

Received: 07.04.2016 Accepted: 23.05.2016
Results. PDM011011-capsule (1.2 g/day) showed significant reduction in FPG level by $14.59 \%$ after 90 days treatment, while patients receiving placebo capsules exhibited a marginal increase of $2.12 \%$. The reduction in FPG level was statistically significant $(p=0.013)$ as compared with the placebo group. It also reduced PPG level by $22.21 \%$ as compared to the $3.71 \%$ reduction $(p=0.002)$ in placebo group. The encouraging reduction in $\mathrm{HbA}_{1 \mathrm{c}} \%$ in the drug group was 0.78 as compared to the placebo group with only 0.20 ( $p=0.066$ ). PDM011011 capsule showed no adverse events, serious adverse events and death in the study population. Conclusion. PDM011011-capsule (1.2 g/day) showed good efficacy and safety; and it can be prescribed as an adjuvant therapy in subjects with T2DM. (Clin Diabet 2016; 5, 3: 88-94)

Key words: type 2 diabetes mellitus, Momordica charantia, Glycebal, PDM011011 capsule, hypoglycemic, antidiabetic

\section{Introduction}

Diabetes mellitus (DM) is a progressive metabolic disorder characterized by increased blood glucose level for a long duration, insulin deficiency and insulin resistance with disturbances of carbohydrate, fat and protein metabolism [1]. The long term hyperglycemia is associated 
with macro and microvascular complications (dysfunction or failure of vital organs including eyes, heart, kidney, nerves and blood vessels) [2]. As per annual report of the international diabetes federation, 387 million people have DM and it will reach to 592 million by 2035 [3]. DM is predicted to affect 79.4 million people in India by 2030 and the prevalence is increasing in rural population [4].

Type 2 DM (T2DM) predominantly occurs between age 45-64 and its development is based on various factors, including genetics, physical inactivity, sedentary lifestyle, obesity, smoking and substantial consumption of alcohol [5]. Pathophysiological conditions in T2DM are due to impaired insulin secretion by pancreatic $\beta$ cells and insulin resistance or both. The reduction in insulin secretion is established gradually and comprises glucose and lipid toxicity [6].

In available treatment options, oral hypoglycemic agents and insulin supplement is backbone for management of DM. However, these are associated with side effects and fail to alter the progress of complications [7]. The most common side effects observed are hypoglycemia, increased body weight (Sulfonylureas, Meglitinides), peripheral edema, impaired liver function (Thiazolidinediones) [8] and gastrointestinal disorders (Dipeptidyl Peptidase-4 Inhibitors) [9]. Thiazolidinedione class is also allied with adverse effects mainly high risk of heart attack and bladder cancer $[10,11]$.

Herbal medicines are now in great demand for the treatment of DM as they are efficacious, produce relatively less or no side effects and are of relatively low cost compared with insulin and other oral hypoglycemic drugs $[12,13]$.

Momordica charantia (family Cucurbitaceae), bitter melon or bitter gourd is a medicinal plant used traditionally for treatment of various diseases and known for various pharmacological activities [14]. Studies conducted in streptozotocin induced diabetic rats and mice with Bitter melon have shown significant reduction of blood glucose levels [15]. Khanna et al. isolated polypeptide-p, from $M$. charantia which has shown effective hypoglycemic activity [16]. In many clinical studies $M$. charantia has shown beneficial effects in diabetic subjects $[17,18]$. $M$. charantia is identified to contain several compounds such as mormordin, carotenoids, flavonoids, vitamin C, and polyphenols. The important compounds that have isolated from $M$. charantia and known as hypoglycemic agents include charantin (a steroid glycoside), and polypeptide-p or plant insulin [19].

Existing marketed formulations containing bitter melon juice powder prepared by traditional methods may have risk of degradation of biomolecules before use. We developed a patented, novel method for the preparation of $M$. charantia juice powder which assures the stability of heat sensitive biomolecules. The present study was performed to evaluate the efficacy and safety of PDM011011 capsule as an adjuvant therapy in subjects with T2DM.

\section{Materials and methods} Patients

Male or female patients of age $>30$ and $<70$ years with a clinical diagnosis of T2DM, stable for 6 months on any other anti-diabetic agents, prior to screening were recruited from 5 centers in India. Patients having fasting plasma glucose of $\geq 110 \mathrm{mg} / \mathrm{dl}$ and $\leq 250 \mathrm{mg} / \mathrm{dl}$; $\mathrm{HbA}_{1 \mathrm{c}}>7 \%$, but $<10 \%$ at the time of randomization were included. Pregnant and lactating women, women of childbearing potential and men not agreeing to use adequate contraception methods during study, were excluded. Other exclusion criteria were subjects with type $1 \mathrm{DM}$, secondary DM, and clinically significant cardiac disease, endocrine abnormalities other than stable thyroid disease or patients requiring insulin therapy and serum creatinine level more than $1.5 \mathrm{mg} / \mathrm{dl}$.

The study was approved by an Institutional Review Boards and conducted in accordance with the ethical principles described in the Declaration of Helsinki. Written informed consent was taken from all subjects prior to start of the study.

\section{Plant material and drug preparation}

Unripe green fruits of $M$. charantia, collected from the fields of Maharashtra, India were authenticated in Piramal Life Sciences Limited (PLSL), Mumbai India. The extraction process focuses on the juice expression of whole fruits with seeds, which is then processed and converted into a free-flowing natural green colored powder with a characteristic odor and taste. The processing of juice is a patented step, developed for the stabilization of heat sensitive bioactives. Each PDM011011-capsule contained $400 \mathrm{mg}$ of dry standardized fruit juice powder with not less than $0.4 \mathrm{mg}$ of Uridine as a chemical marker.

\section{Study design}

The present study was an open-label, randomized, active-controlled, phase II trial to evaluate efficacy and safety of PDM011011 capsules as an adjuvant therapy in subjects with T2DM. The study design consisted of total 5 visits; a screening visit, baseline visit, followed by three visits on day 30,60 and 90, at which safety and efficacy assessments were performed. A total of 93 patients were screened and 85 patients were enrolled at 5 sites in India. The eligible 85 subjects were randomized into 3:1 ratio in drug treatment (PDM011011-capsule) and placebo arm. Sixty-four patients received 
Table 1. Patient disposition in the study

\begin{tabular}{|c|c|c|c|}
\hline \multirow[t]{3}{*}{ Disposition } & \multicolumn{2}{|c|}{ Number (\%) of patients } & \multirow{3}{*}{$\begin{array}{c}\text { Total } \\
\mathrm{N}=85\end{array}$} \\
\hline & Study drug (PDM 011011) & Placebo & \\
\hline & $N=64$ & $N=21$ & \\
\hline Enrolled subjects & $64(75.29 \%)$ & $21(24.70 \%)$ & $85(100 \%)$ \\
\hline Subjects dosed & $64(75.29 \%)$ & $21(24.70 \%)$ & $85(100 \%)$ \\
\hline Completed & $62(78.48 \%)$ & $17(21.51 \%)$ & 79 (92.94\%) \\
\hline Prematurely withdrawn from study & $02(3.12 \%)$ & $04(9.52 \%)$ & $06(4.70 \%)$ \\
\hline Consent withdrawn & $0(0.00 \%)$ & $0(0.00 \%)$ & $0(0.00 \%)$ \\
\hline Investigator decision & $0(0.00 \%)$ & $0(0.00 \%)$ & $0(0.00 \%)$ \\
\hline Ineligibility/Not meeting incl. criteria & $0(0.00 \%)$ & $0(0.00 \%)$ & $0(0.00 \%)$ \\
\hline $\mathrm{AE}$ & $0(0.00 \%)$ & $0(0.00 \%)$ & $0(0.00 \%)$ \\
\hline Lost to follow-up & $2(3.12 \%)$ & $4(9.52 \%)$ & $6(19.04 \%)$ \\
\hline SAE/Death & $0(0.00 \%)$ & $0(0.00 \%)$ & $0(0.00 \%)$ \\
\hline Other & $0(0.00 \%)$ & $0(0.00 \%)$ & $0(0.00 \%)$ \\
\hline
\end{tabular}

$\mathrm{N}$ - number of patients; $\mathrm{AE}$ - adverse events; SAE - serious adverse events

PDM011011 capsules ( $1.2 \mathrm{~g} /$ day) while 21 patients received placebo capsules for 90 days. Drug treatment arm received one PDM011011-capsule (400 mg) in the morning and two capsules in evening daily half-anhour before breakfast and dinner respectively. Similarly placebo capsules were received in the placebo arm.

\section{Efficacy and safety assessment}

The primary efficacy endpoints were mean change in fasting plasma glucose (FPG), postprandial blood sugar level (PPG) level and glycosylated hemoglobin $\left(\mathrm{HbA}_{1 \mathrm{c}}\right) \%$ from baseline to day 30,60 and 90 after interventions. $\mathrm{HbA}_{1 \mathrm{c}} \%$ should be $\geq 7$. The secondary efficacy endpoints were lipid profile and the general well-being of subjects during the treatment. Safety was monitored by assessing patient's reported adverse events, physical examinations, vital signs, clinical laboratory parameters as well as complete blood count.

\section{Sample size and randomization}

Determination of sample size was based on the outcome of oral treatment of the same drug and study's assumption was done as follows: efficacy of the test drug $(70 \%, 42$ out of 60$)$ and placebo $(40 \%, 8$ out of $20)$ will have about $90 \%$ power to detect differences at alpha $=0.05$. The randomization of all enrolled subjects was carried out by block randomization in 3:1 ratio (drug:placebo).

\section{Statistical analysis}

Statistical analysis was performed by using SPSS V 10.0 package (Statistical Package for the Social Sciences, Version 10.0). Data was given as Mean \pm SD or Frequency (Percentage) as per the type of data. Stu- dent's paired' $t$ ' tests were applied to compare means of related (before-after) data. Student's unpaired' $t$ ' tests were applied to compare means of unrelated data. Level of significance was taken as $p=0.05$.

\section{Results}

\section{Demographic and baseline characteristics}

Out of 85 enrolled subjects, 79 completed the study, including 62 patients from PDM011011 group and 17 from the placebo group (Table 1). Six patients were lost to follow up; 2 from treatment group and 4 from the placebo group and hence could not complete the study (Figure 1). The trial was performed in a realworld clinical setting involving 5 Indian sites, started in June 26, 2012 and completed in October 17, 2012.

The demographic data evaluation was performed. The protocol population and the baseline characteristics were found comparable between the two groups (Table 2). The range of age in the study drug was 31-60 years and in the placebo group it was 31-55, thus similar age-wise distribution in both the groups was observed.

The baseline disease characteristics (Table 2) in terms of FPG, PPG level and $\mathrm{HbA}_{1 \mathrm{c}} \%$ were evaluated. The mean baseline FPG level in PDM 011011-group was $150.02 \pm 35.2 \mathrm{mg} / \mathrm{dl}$ while in the placebo group it was $148.76 \pm 34.8 \mathrm{mg} / \mathrm{dl}$. The mean baseline PPG level was $202.40 \pm 56.7 \mathrm{mg} / \mathrm{dl}$ in the treatment group and $190.24 \pm 54.3 \mathrm{mg} / \mathrm{dl}$ in the placebo group. The mean baseline $\mathrm{HbA}_{1 \mathrm{c}}$ \% level in the treatment group was 7.87 \pm 1.0 and in the placebo group $7.83 \pm 1.1$ respectively.

\section{Efficacy analysis}

Primary efficacy end point assessments consisted of three parameters - FPG level, PPG level and $\mathrm{HbA}_{1 \mathrm{c}} \%$ 


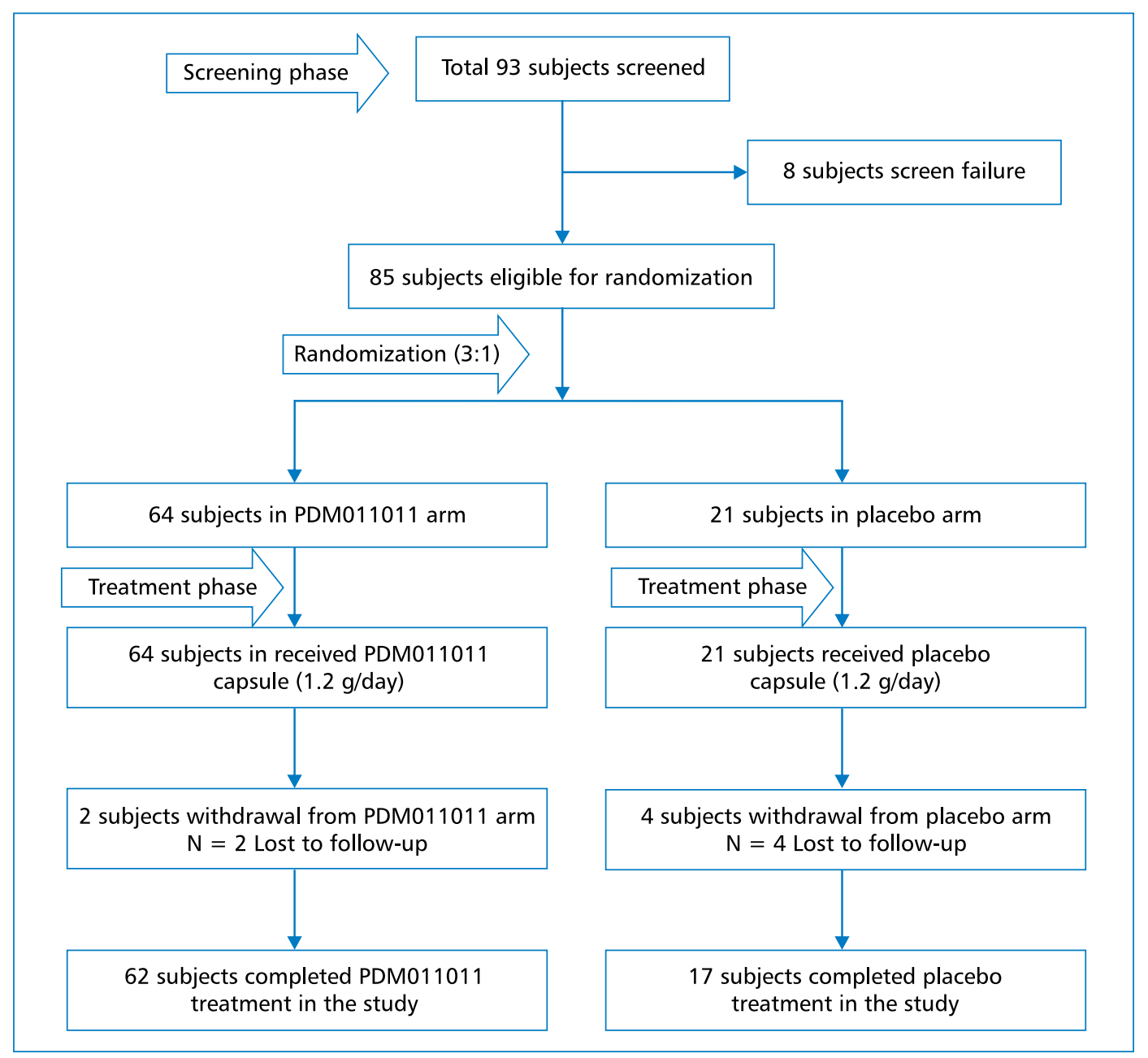

Figure 1. CONSORT Flow Diagram (Patient disposition)

Table 2. Patient demographics and baseline characteristics

\begin{tabular}{|c|c|c|}
\hline Parameter & $\begin{array}{l}\text { PDM } 011011 \text { treatment group } \\
\qquad \mathrm{N}=62\end{array}$ & $\begin{array}{l}\text { Placebo group } \\
\qquad \mathrm{N}=17\end{array}$ \\
\hline \multicolumn{3}{|l|}{ Gender, n (\%) } \\
\hline Male & $39(62.90 \%)$ & $10(58.82 \%)$ \\
\hline Female & $23(37.09 \%)$ & $07(41.50 \%)$ \\
\hline \multicolumn{3}{|l|}{ Age } \\
\hline Mean age $\pm S D$ & $41.33 \pm 7.59$ & $41.31 \pm 6.88$ \\
\hline Age range & $31-60$ & $31-55$ \\
\hline Mean baseline FPG level \pm SD [mg/dl] & $150.02 \pm 35.2$ & $148.76 \pm 34.8$ \\
\hline Mean baseline PPG level \pm SD [mg/dl] & $202.40 \pm 56.7$ & $190.24 \pm 54.3$ \\
\hline Mean baseline $\mathrm{HbA}_{1 \mathrm{c}} \%$ level $\pm \mathrm{SD}$ & $7.87 \pm 1.0$ & $7.83 \pm 1.1$ \\
\hline \multicolumn{3}{|l|}{ Past/Receiving medications } \\
\hline Glibenclamide & 14 & 03 \\
\hline Gliclazide & 02 & 01 \\
\hline Metformin & 19 & 07 \\
\hline Gliclazide with metformin & 16 & 05 \\
\hline Glimpride & 05 & 00 \\
\hline Herbal & 02 & 01 \\
\hline Unknown & 05 & 02 \\
\hline
\end{tabular}

FPG — fasting plasma glucose level; PPG — postprandial blood sugar level; $\mathrm{HbA}_{1 c}$ - glycosylated hemoglobin 
Table 3. Summary statistics of fasting, postprandial blood sugar level and $\mathrm{HbA}_{1 \mathrm{c}} \%$

\begin{tabular}{|c|c|c|c|c|c|}
\hline Variable & Group & Baseline & Day 30 & Day 60 & Day 90 \\
\hline \multirow[t]{2}{*}{$\mathrm{FPG}[\mathrm{mg} / \mathrm{dl}]$} & Drug & $150.02 \pm 35.2$ & $142.5 \pm 21.2$ & $135.43 \pm 24.8$ & $128.12 \pm 16.8$ \\
\hline & Placebo & $148.76 \pm 34.8$ & $145.35 \pm 21.0$ & $146.35 \pm 21.3$ & $150.88 \pm 22.8$ \\
\hline \multirow[t]{2}{*}{ PPG [mg/dl] } & Drug & $202.4 \pm 56.7$ & $179.16 \pm 22.6$ & $170.01 \pm 26.4$ & $157.45 \pm 17.9$ \\
\hline & Placebo & $190.23 \pm 54.2$ & $182.23 \pm 28.3$ & $182.76 \pm 32.1$ & $183.17 \pm 30.5$ \\
\hline \multirow[t]{2}{*}{$\mathrm{HbA}_{1 \mathrm{c}} \%$} & Drug & $7.87 \pm 1.0$ & - & - & $7.08 \pm 0.9$ \\
\hline & Placebo & $7.83 \pm 1.1$ & - & - & $7.62 \pm 0.9$ \\
\hline
\end{tabular}

Values expressed as mean \pm SD; Drug — PDM011011 capsule; FPG — fasting plasma glucose level; PPG — postprandial blood sugar level; $\mathrm{HbA}$ 1c — glycosylated hemoglobin

Table 4. Percent change in primary efficacy parameters after treatment

\begin{tabular}{|c|c|c|c|c|c|c|}
\hline \multirow[t]{2}{*}{ Parameters } & \multicolumn{2}{|c|}{ FPG [mg/dl] } & \multicolumn{2}{|c|}{ PPG [mg/dl] } & \multicolumn{2}{|c|}{$\mathrm{HbA}_{1 \mathrm{c}}(\%)$} \\
\hline & Drug & Placebo & Drug & Placebo & Drug & Placebo \\
\hline Baseline & 150.02 & 148.76 & 202.40 & 190.24 & 7.87 & 7.83 \\
\hline Post treatment (90 days) & 128.13 & 150.88 & 157.45 & 183.18 & 7.08 & 7.62 \\
\hline Plasma glucose decrease during treatment period & 21.89 & -2.12 & 44.95 & 7.06 & - & - \\
\hline Plasma glucose decrease (\%) & 14.59 & -1.42 & 22.21 & 3.71 & 0.78 & 0.20 \\
\hline$p$ value & \multicolumn{2}{|c|}{${ }^{*} p=0.013$} & \multicolumn{2}{|c|}{$* * p=0.002$} & \multicolumn{2}{|c|}{$p=0.066$} \\
\hline
\end{tabular}

Data was evaluated using Student's unpaired t test; *Significant values at $p<0.05$ compared to the placebo; **Significant values at $p<0.01$ compared to the placebo; Drug — PDM011011 capsule; FPG — fasting plasma glucose level; PPG — postprandial blood sugar level; $\mathrm{HbA}_{1 \mathrm{c}}$ — glycosylated hemoglobin

Table 5. Lipid profiling of subjects after treatment

\begin{tabular}{llcc}
\hline Variable & \multicolumn{1}{c}{ Treatment } & Baseline & Day 90 \\
\hline Serum cholesterol [mg/dl] & PDM011011 Drug & $152.69 \pm 27.27$ & $146.48 \pm 28.74$ \\
& Placebo & $154.23 \pm 30.11$ & $152.35 \pm 29.11$ \\
HDL cholesterol [mg/dl] & PDM011011 Drug & $48.56 \pm 5.93$ & $47.52 \pm 9.28$ \\
& Placebo & $48.52 \pm 5.83$ & $48.06 \pm 7.71$ \\
LDL cholesterol [mg/dl] & PDM011011 Drug & $81.82 \pm 24.15$ & $77.45 \pm 26.10$ \\
& Placebo & $84.16 \pm 25.22$ & $81.99 \pm 23.38$ \\
VLDL cholesterol [mg/dl] & PDM011011 Drug & $22.31 \pm 4.20$ & $21.51 \pm 3.95$ \\
Triglycerides [mg/dl] & Placebo & $21.54 \pm 4.68$ & $22.31 \pm 4.64$ \\
& PDM011011 Drug & $111.55 \pm 20.98$ & $107.56 \pm 19.75$ \\
\hline
\end{tabular}

Values expressed as mean \pm SD; HDL — high density lipoprotein; LDL — low density lipoprotein; VLDL — very low density lipoprotein

as depicted in Table 3. The study drug showed significant reduction of FPG level by $14.59 \%$ after 90 days treatment, while placebo group exhibited a marginal increase of $2.12 \%$ (Table 4 ). This reduction was statistically significant $(p=0.013$ ) when compared with the placebo group. The study drug also reduced PPG level by $22.21 \%$ as compared to the $3.71 \%$ reduction ( $p=0.002$ ) in the placebo group. However, there was no significant reduction observed in $\mathrm{HbA}_{1 \mathrm{c}} \%$ in both drug and placebo treated groups. The reduction in
$\mathrm{HbA}_{1 c} \%$ in the drug group which was 0.78 as compared to the placebo group with only 0.20 ( $p=0.066$ ) was encouraging.

Secondary efficacy endpoint assessments contain the lipid profiling of serum cholesterol, HDL (high density lipoprotein), LDL (low density lipoprotein), VLDL (very low density lipoprotein) and triglycerides. There was a reduction in the mean change from baseline to day-90 observed in both treatment and placebo group (Table 5). 


\section{Safety analysis}

Safety analysis was carried out in terms of incidence of adverse events, hematological parameters, vital signs and physical examination. Treatment of PDM011011-capsule was well tolerated throughout the study. During 90 days treatment with PDM011011-capsule no adverse events or serious adverse events as well as no death was recorded. There was no significant change in the hematological parameters, blood chemistry and vital signs seen.

\section{Discussion}

The treatment with PDM011011-capsule significantly reduced FPG level and PPG level, which confirms good hypoglycemic activity of the treatment drug. Treatment with PDM011011 capsules (1.2 g/day) for 3 months reduced the FPG level by $14.59 \%$, while slight increase of $2.12 \%$ was observed in patients receiving placebo capsules. The reduction in FPG level was statistically significant $(p=0.013$ ) as compared with the placebo group. Rahman et al. mentioned significant reduction of the FPG level after treatment of $2 \mathrm{~g} /$ day and $4 \mathrm{~g}$ /day bitter melon powder for 10 weeks in T2DM patients [20]. In another study, it was observed that a $2 \mathrm{~g} /$ day dose of bitter melon for 4-weeks in T2DM patients significantly reduced blood glucose level by $26.7 \pm 40.8 \mathrm{mg} / \mathrm{dl}$ however the effect was less as compared to $1 \mathrm{~g} /$ day dose of metformin [21]. In our study, results reported with lower dose ( $1.2 \mathrm{~g} /$ day) are found similar to the results reported with higher doses ( $2 \mathrm{~g} / \mathrm{day}$ and $4 \mathrm{~g} /$ day) in other studies $[20,21]$.

In this study, the PPG level was also reduced by $22.21 \%$ as compared to the $3.71 \%$ reduction $(p=0.002)$ in placebo after 90 days treatment. John et al. reported non-significant reduction ( $p>0.05$ ) in PPG level after treatment with bitter melon tablets (total $6 \mathrm{~g} /$ day) for 4 weeks in T2DM patients. The change in PPG was $30 \mathrm{mg} / \mathrm{dl}$ observed from baseline to endpoint [22]. In our study the most significant change in PPG was $44.95 \mathrm{mg} / \mathrm{dl}$ seen from baseline to day- 90 .

The measurement of $\mathrm{HbA}_{1 \mathrm{c}} \%$ is the hallmark for overall control of diabetes and preventing associated complications [23]. A decline of $1 \% \mathrm{HbA}_{1 \mathrm{c}}$ might avert about $30-35 \%$ microvascular and $14-16 \%$ macrovascular complications [24]. Our study-results denote that, a reduction in $\mathrm{HbA}_{1 \mathrm{c}} \%$ from baseline to end point in patients receiving PDM011011 capsules is higher than the placebo treated group. At day-90 the difference between mean reductions in $\mathrm{HbA}_{1 c} \%$ was not statistically significant. These results were found similar to the study reported by Dans et al. in which non-significant decline in $\mathrm{HbA}_{1 \mathrm{c}} \%$ levels was seen in T2DM patients treated with bitter melon extract [25]. Rahman et al. also reported non-significant reduction in $\mathrm{HbA}_{1 \mathrm{c}} \%$ in $\mathrm{T} 2 \mathrm{DM}$ patients receiving bitter melon powder for 10 weeks [20].

In our previous study, we assessed the effect of PDM011011-capsule (400 $\mathrm{mg}$ ) bid in T2DM patients ( $n=20$ ) for 90 days. The reduction of FPG and PPG levels were $18.65 \%$ and $22.03 \%$ respectively, and $1.1 \%$ reduction in the level of $\mathrm{HbA}_{1 \mathrm{c}} \%$ were observed. The outcomes of this pilot-study were comparable with present study. In addition, approximately 5\% reduction in the body weight was observed in obese diabetes patients $(n=6)$ with weight $(80 \mathrm{Kg})$ receiving PDM011011 capsules. Overall, 2.2\% weight reduction was observed in diabetes patients and $0.6 \%$ weight gain was seen in patients receiving metformin tablets. The weight reduction is also an added improvement of PDM011011 capsule.

In the present study, the treatment of PDM011011-capsule in T2DM patients showed a mean reduction in levels of serum cholesterol, LDL cholesterol, VLDL cholesterol and triglycerides from baseline to the endpoint. These findings are similar to the study outcomes reported by Rahman et al. where the groups treated with bitter melon powder exhibited favorable changes in the blood lipid levels but not reached statistical significance excluding the $4 \mathrm{~g} /$ day group [20].

PDM011011 capsule ( $1.2 \mathrm{~g} /$ day) was well tolerated and found to be safe during this study. Hematological parameters and vital signs were reported normal in both treatment and placebo group. In the overall response assessed at the end of the study, all subjects showed excellent response to PDM011011-treatment, $80 \%$ (49 out of 62 ). The remarkable reduction in the fasting glucose level, postprandial blood glucose level and $\mathrm{HbA}_{1 \mathrm{c}} \%$ confirms the anti-diabetic potential of PDM011011-capsule. It can be prescribed with other anti-diabetic drugs as adjuvant therapy in T2DM patients. Although PDM011011-capsule showed good efficacy, longer duration of clinical study is necessary to confirm the long term safety of the drug.

\section{Conclusion}

Glycebal-PDM011011 capsule showed good efficacy and safety; and it can be prescribed as an adjuvant therapy in subjects with type 2 diabetes mellitus.

\section{Conflict of interest statement}

The authors declare no conflict of interests.

\section{Acknowledgement}

We are indebted to Dr. G. Tyebkhan for her expert comments and review of the manuscript, K. Salkar for administrative support and Karmic Lifesciences LLP for drafting of the manuscript. 


\section{REFERENCES}

1. World Health Organization [Internet]. Diabetes Programme. WHO c-2016 [cited 2016 Mar 10] Available from: http://www.who.int/ /diabetes/action_online/basics/en/.

2. American Diabetes Association. Diagnosis and classification of diabetes mellitus. Diabetes Care 2010; 33 Suppl 1: S62-69. doi: 10.2337/dc10-S062.q1.

3. International Diabetes Federation [Internet]. [cited 2016 Mar 10] In: Diabetes Atlas 6th ed. 2014 Update. Available from: http:// //www.idf.org/sites/default/files/Atlas-poster-2014_EN.pdf.

4. Kaveeshwar SA, Cornwall J. The current state of diabetes mellitus in India. Australas Med J 2014; 7: 45-48.

5. Olokoba AB, Obateru OA, Olokoba LB. Type 2 Diabetes Mellitus: A Review of Current Trends. Oman Med J 2012; 27: 269-273.

6. Kohei K. Pathophysiology of Type 2 Diabetes and Its Treatment Policy. JMAJ 2010; 53: 41-46.

7. Mohammady I, Elattar S, Mohammed S, Ewais M. An Evaluation of Anti-Diabetic and Anti-Lipidemic Properties of Momordica charantia (Bitter Melon) Fruit Extract in Experimentally Induced Diabetes. Life Sci J 2012; 9: 363-374.

8. Scheen AJ. Thiazolidinediones and liver toxicity. Diabetes Metab 2001; 27: 305-313.

9. Mallare JT, Karabell AH, Velasquez-Mieyer P, Stender SRS, Christensen ML. Current and future treatment of metabolic syndrome and Type 2 diabetes in children and adolescents, Diabetes Spectr 2005: 18: 221-225.

10. Doctors concerned as India suspends diabetes drug pioglitazone. Medscape. Jul 08, 2013. [cited 2016 Mar 12] Available from: http://www.medscape.com/viewarticle/793301.

11. Shukla R, Kalra S. Pioglitazone: Indian perspective. Indian J Endocrinol Metab 2011; 5: 294-297.

12. Prabhakar PK, Doble M. Mechanism of action of medicinal plants towards diabetes mellitus: A review, In: Govil JN, Singh VK, Bhardwaj R, editors. (eds). Recent Progress in Medicinal Plants (2008a), Vol. 22, Studium Press: LLC, USA

13. Patel DK, Kumar R, Laloo D, Hemalatha S. Diabetes mellitus: An overview on its pharmacological aspects and reported medicinal plants having antidiabetic activity. Asian Pac J Trop Biomed 2012; 2: 411-420.
14. Sathish Kumar D, Vamshi Sharathnath K, Yogeswaran P et al. A Medicinal Potency of Momordica charantia. Int J Pharm Sci Rev Res 2010; 1: 95-100.

15. Day C, Cartwright T, Provoct J, Bailey CJ. Hypoglycaemic effect of Momordica charantia extracts. Planta Med 1990; 54: 426-429.

16. Khanna P, Jain SC, Panagariya A, Dixit VP. Hypoglycemic activity of polypeptide-p from a plant source. J Nat Prod 1981; 44: 648-655.

17. Ghorbani A. Best herbs for managing diabetes: A review of clinical studies. Braz J Pharm Sci 2013; 49: 413-422.

18. Lim ST, Jimeno CA, Razon-Gonzales EB, Velasquez MN. The MOCHA DM study: The effect of Momordica charantia tablets on glucose and insulin levels during the postprandial state among patients with Type 2 Diabetes Mellitus. Philipp J Intern Med 2010; 48: 18-25.

19. Nerurkar PV, Lee YK, Motosue M, Adeli K, Nerurkar VR. Momordica charantia (bitter melon) reduces plasma apolipoprotein B-100 and increases hepatic insulin receptor substrate and phosphoinositide-3 kinase interactions. Br J Nutr 2008; 100: 751-759.

20. Rahman IU, Khan RU, Rahman KU, Bashir M. Lower hypoglycemic but higher antiatherogenic effects of bitter melon than glibenclamide in type 2 diabetic patients. Nutr J 2015; 14: 13. doi: 10.1186/1475-2891-14-13.

21. Fuangchan $A$, Sonthisombat $P$, Seubnukarn $T$ et al. Hypoglycemic effect of bitter melon compared with metformin in newly diagnosed type 2 diabetes patients. J Ethnopharmacol 2011; 134: 422-428.

22. John AJ, Cherian R, Subhash HS, Cherian AM. Evaluation of the efficacy of bitter gourd (Momordica charantia) as an oral hypoglycemic agent-A randomized controlled clinical trial. Indian J Physiol Pharmacol 2003; 47: 363-365.

23. Landgraf $\mathrm{R}$. The relationship of postprandial glucose to $\mathrm{HbA} 1 \mathrm{c}$. Diabetes Metab Res Rev 2004; 20 Suppl 2: S9-S12.

24. Haddadinezhad S, Ghazaleh N. Relation of fasting and postprandial and plasma glucose with hemoglobin A1 c in diabetics. Int J Diabetes Dev Ctries 2010; 30: 8-10.

25. Dans AM, Villarruz MV, Jimeno CA et al. The effect of Momordica charantia capsule preparation on glycemic control in type 2 diabetes mellitus needs further studies. J Clin Epidemiol 2007; 60: $554-559$ 